\title{
Computational fluid dynamics (CFD) assisted analysis of profiled membranes performance in reverse electrodialysis
}

\author{
Sylwin Pawlowski ${ }^{1}$, Vítor Geraldes², João G. Crespo ${ }^{1}$ and Svetlozar Velizarovi,**
}

1 LAQV-REQUIMTE, DQ, FCT, Universidade NOVA de Lisboa, 2829-516 Caparica, Portugal

2 Department of Chemical Engineering/ICEMS, Instituto Superior Técnico (University of Lisbon), Av. Rovisco Pais 1, 1049-001 Lisbon, Portugal

*Corresponding author: Tel: (+351) 212948314, Fax: (+351) 212948550, E-mail:

s.velizarov@fct.unl.pt

\begin{abstract}
Implementation of reverse electrodialysis (RED) is economically limited by the relatively high ion-exchange membranes price. Additionally, the shadow effect of non-conductive spacers reduces the membrane area available for counter-ion transport and increases the stack electric resistance. A promising alternative could be utilization of profiled membranes, since the reliefs formed on their surface keeps the membranes separated and provides channels for solutions flow. Herein, we have simulated, through computational fluid dynamics (CFD) tools, fluid behavior in channels formed by various profiled membranes. The highest net power density values were obtained for corrugations shape and arrangement in a form of chevrons due to the increase of the available membrane area and an excellent balance between enhancement of mass transfer and the increase of the pressure drop in the channel. When properly designed, corrugated membranes may offer a better performance even compared to the case of conductive spacers. The proposed membrane corrugation design in not limited to the RED application, and could be also extended to other electromembrane processes, such as electrodialysis and Donnan dialysis, in which high ionic mass transport rates are desirable at as low as possible energy costs.
\end{abstract}

\section{Keywords}

Salinity gradient energy, Reverse electrodialysis (RED), Profiled membranes, Computational fluid dynamics (CFD), Net power density 


\section{Introduction}

A potentially sustainable source of energy is the chemical energy associated with solvation of salts known as salinity gradient energy or blue energy. Mixing of two streams with different salt concentrations is spontaneous and releases energy (Gibbs free energy). Power generation from salinity gradients can be achieved by controlled mixing of concentrated and dilute electrolyte solutions in a reverse electrodialysis (RED) operation mode [1-4].

A RED stack consists of a number of alternating cation- and anion-exchange membranes stacked between two electrodes (Figure 1). The mechanical support to create the flow channel compartments and maintain a constant distance between the membranes is usually assured by non-conductive spacers. The compartments are alternately fed with concentrated (e.g., sea water) and dilute (e.g., river water) saline solutions. In such a way, an electric potential difference is established between the electrodes and the cations and the anions migrate in opposite directions, toward the cathode and anode, respectively. This spontaneous ionic current is transformed into electron current at the electrode surfaces. In the electrode compartments, a solution containing, preferably, a homogeneous redox couple is recirculated.

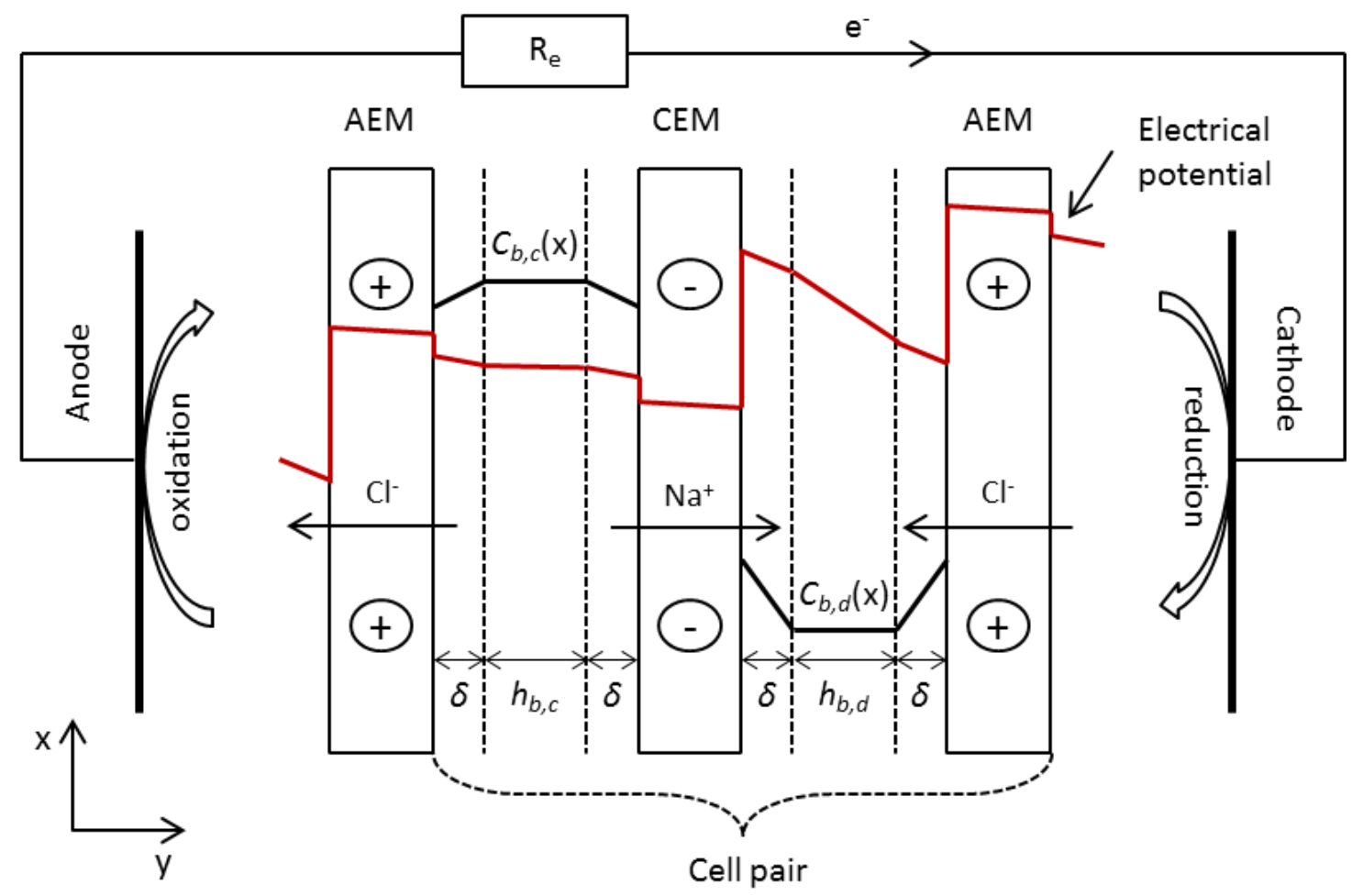

Figure 1. Schematic representation of concentration and electric potential profiles in the compartments of a reverse electrodialysis cell (CEM - cation-exchange membrane, AEM anion-exchange membrane, $R_{e}$ - external load resistance). 
The most appropriate engineering solution for RED optimization requires minimization of the stack internal electric resistance. This is due to the fact that the so-called "shadow" effect of non-conductive spacers over the membrane surface is one of the major contributions for increasing ohmic electric resistance, as the available area for counter-ion transport is significantly reduced [5-10]. For example, in lab-scale RED stacks, it was observed that the internal stack resistance dropped, in average to $67 \%$ of its initial value, when the spacer' nonconductive parts, which taped $50 \%$ of the available membrane area, were completely removed and the intermembrane distance was maintained only by the gasket [10]. The resistance value did not drop proportionally by $50 \%$ since the spacer mesh absence decreased the fluid turbulence, and therefore led to formation of a thicker diffusion boundary layer (DBL).

Operation of a large-scale RED stack with empty channels could be, however, not feasible since such channels may easily collapse. A possible solution, in which the spacers are removed and the intermembrane distance is still maintained constant, even for large membrane areas, is the utilization of profiled membranes [10-11]. Profiled membranes, also known as corrugated membranes, provide channels for the feed streams, while the relief formed on their surfaces keeps the membranes separated [12-15]. Profiled membranes have been successfully used for filtration [15-19], gas permeation [20-21] and some electromembrane applications [22-24].

For power generation by reverse electrodialysis, the advantages of using profiled membranes, instead of non-conductive spacers, consists in a decreased internal electric resistance, an increased membrane effective area for counter-ion transport, a lower hydraulic friction (lower pressure drop) and reduced fouling [6-7, 12, 14, 22, 25-26]. Several profiled membrane geometries and configurations have been used with different success [7, 25]. For example, subcorrugations perpendicular to the fluid flow did not proved to be beneficial as no additional mixing was observed and the non-ohmic resistance was mainly dominated by the fluid distribution [7] due to the existence of dead zones and preferential flow channeling [27].

So far, the best experimental results [25] and theoretical predictions [28] were obtained for corrugations with a round pillar structure as they enable a more uniform fluid distribution over the entire membrane surface area. However, at low linear flow velocities $(\operatorname{Re}<3)$, at which the highest net power density values can be obtained, the concentration polarization in channels with profiled membranes was found to be higher compared to the cases in which the channels are empty or with spacers [28]. This may be related to the observation that the distance between the corrugations must be optimized in order to avoid formation of dead zones [29]. Therefore there is still a need to find new profile geometries that provide a better fluid distribution, increase the effective membrane area available for ion transport and minimize concentration polarization effects. 
The DBL thickness in RED stack can be calculated from experimental data (obtained through dimensionless mass-transfer correlations based on the film theory [10]. Utilization of masstransfer correlations (sometimes even such obtained for convective-diffusive systems without any charge transfer) has been the common practice during the last decades for dimensioning electrodialysis stacks [30-34]. However, as these correlations are specific for a given channel geometry, for new geometries new correlations must be developed.

In case of laminar flow, which is common for RED channels, computational fluid dynamics (CFD) can estimate mass-transfer coefficients, as well as pressure drop, in a very accurate and reliable way [35]. Firstly, the flow patterns and concentration distribution inside the channels are obtained by solving the mass continuity and Navier-Stokes equations [35-39]. Then, the mass transfer coefficients are computed at the relevant interfaces, where interfacial mass transfer occurs [35-36].

In the present study, parameters such as available membrane area, pressure drop, and mass transfer coefficient, as well as flow entrance effects on mass transfer were considered. The effect of corrugations shape, height and spatial distribution was analyzed on the basis of the obtainable net power, which had been normalized by the flat membrane area before corrugated. More than twenty different corrugation shapes and arrangements were initially screened and compared by performing 2D simulations, for being faster and less demanding in terms of computational effort. Then, 3D simulations of more complex corrugations forms were performed. The highest net power density gain (by around $76 \%$ ) relatively to channels with non-conductive spacers was estimated for a corrugation in the form of chevrons, which use has not yet been reported for any membrane-based application.

\section{Modeling}

\subsection{Strategy}

Certainly, the most accurate approach to obtain mass transfer coefficient values in the DBLs would be to solve simultaneously the Navier-Stokes-Nernst-Planck-Poisson equations, which would yield the concentration and electric potential fields. However, due to the relatively small contribution of the $\mathrm{DBL}$ resistances to the total electric resistance, applying such a complex approach appears unreasonable.

Therefore, at the membrane surface, the solute continuity equation was solved with a boundary condition of a constant solute concentration. With this approach, it was possible to decouple reasonably well the mass transfer coefficient from the variation of the solute flux along the channel. Another possibility would have been to perform simulations assuming a constant 
solute flux through the membranes or mixed boundary conditions of the Robin type [40]. The mass transfer coefficient value is slightly affected by the chosen boundary condition; however, for a laminar regime, the differences are lower than $20 \%$ [41]. We also decoupled the computation of the solute concentration field from the velocity field, because the time scale of momentum transport was at least one order of magnitude lower compared to the time scale of mass transport.

The CFD simulations were performed using periodic inlet/outlet boundary conditions until the concentration distribution in the channel becomes quasi-periodic. In practice, this means that the channel has been divided into small sections with the same repetitive geometry, where the outlet boundary conditions of one section correspond to the inlet boundary conditions of the next section. In such a way, instead of simulating simultaneously the whole channel, the fluid behavior and concentration profiles are estimated section by section. The evolution of concentration distribution along the channel length can be followed since $x=u \cdot t$, where $u$ is the linear flow velocity, $x$ is the section distance from the channel entrance and $t$ is the residence time required for a fluid element to reach that section. This approach significantly (by at least one order of magnitude) reduces the required computational time, and allows for simulating simultaneously different channel lengths, as was previously proven with a high confidence [35, 42].

Figure 2 presents the modelling strategy steps performed: CFD computing of the solute concentration distribution in a small, repetitive section of the channel (Figure 2a), estimation of average diffusion boundary layer thickness at this channel section (Figure 2b) and, finally, estimation of equivalent channel thickness (Figure $2 \mathrm{c}$ ). These steps were successively repeated along the entire channel length with a final objective of allowing normalizing the estimated obtainable power by a nominal (flat) membrane area, in order to compare different corrugation designs. The nominal effective membrane area is in fact identical to the flat membrane area produced by membrane manufacturers. 


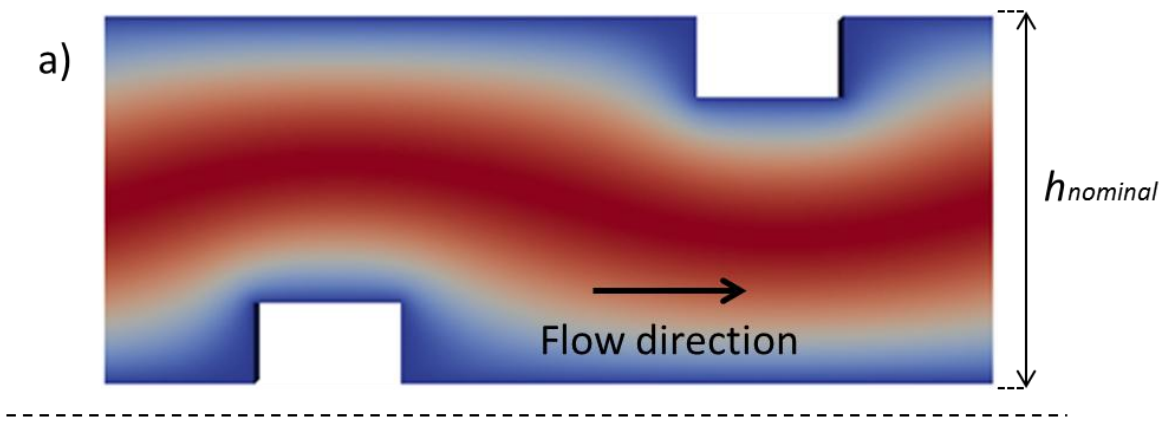

b)
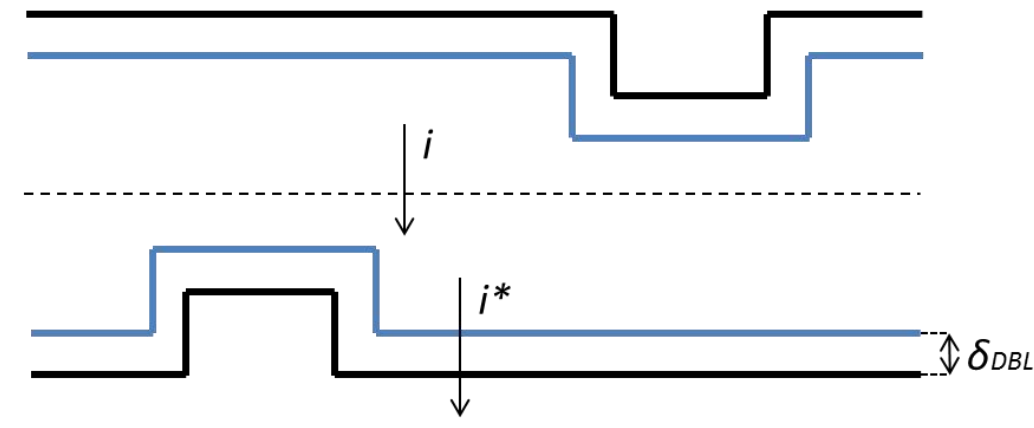

c)

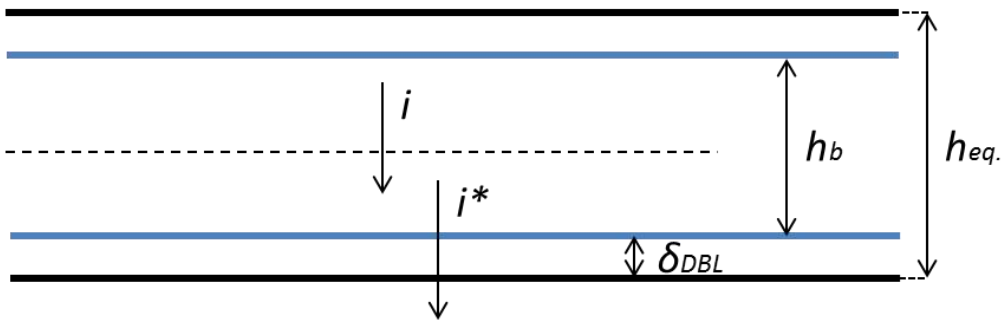

Figure 2. Scheme of the followed modeling strategy. a) Computed concentration distribution in a repetitive section of the RED channel (Solute concentration decreases from red to blue color),

b) Estimation of average diffusion boundary layer thickness in that channel section (eqs. 10-11),

c) Calculation of channel equivalent thickness (eq. 1).

The equivalent thickness of the channel formed by profiled membranes was calculated using the channel' porosity $(\varepsilon)$ :

$h_{e q}=\varepsilon \cdot h_{\text {nominal }}$

where $h_{\text {nominal }}$ is the channel thickness without corrugations. The channel porosity was estimated taking into account the volume occupied by corrugations ( $V_{\text {corrugations }}$ ) compared to the volume of the channel without corrugations $\left(V_{\text {emptry }}\right)$ :

$\varepsilon=\frac{V_{\text {empty }}-V_{\text {corrugations }}}{V_{\text {empty }}}$

Since in a river-sea system the main electric resistance of a RED stack is mainly offered by the dilute stream (river water) compartment [5, 10,43-46], the net power density is strongly influenced by the membrane area offered by a given corrugation geometry. Therefore, for each 
simulation of a channel formed by profiled membranes, we simulated as well an empty (composed by flat membranes) channel with a height equal to the equivalent channel thickness for the profiled membrane case.

Then, we defined a $\theta$ parameter ratio between the maximal net power densities values obtained at the same linear flow velocity for a channel with corrugations $\left(P_{\text {net(profiled })}\right)$ and for an empty channel with the same equivalent height ( $\left.P_{\text {net(empty) }}\right)$ :

$\theta=\frac{\left.P_{\text {net }} \text { (profiled }\right)}{P_{\text {net }(\text { empty })}}$

Due to the same channel equivalent thickness in a stack with profiled and with flat membranes, and, thus, the same ohmic resistance for both stacks, the difference in net power density can be attributed to the effect of corrugations geometry on mass transfer and pressure drop. A $\theta$ ratio values above 1 means that the corrugations have led to an increase in mass transfer coefficient, which is higher in comparison of the increase in pressure drop. A $\theta$ ratio value below 1 means that the pressure drop increase is higher than the increase (if existing), in mass transfer coefficient.

\subsection{Model}

The main objective of the performed CFD simulations was to predict the mass transfer coefficient values. In order to decouple the prevision of diffusion boundary layer thickness from the charge transfer phenomena, the approach followed was based on a formalism assuming mass transfer in a binary salt $(\mathrm{NaCl})$ aqueous solution system with permeable walls and without charge transfer [33].

In the performed CFD simulations, the considered governing equations for incompressible flow of a Newtonian fluid were the mass continuity and Navier-Stokes equations as follows [35-39]:

$\nabla \boldsymbol{U}=0$

$\frac{\partial \rho U}{\partial t}+(u \cdot \nabla) \rho \boldsymbol{U}-\nabla \cdot(\mu \nabla \boldsymbol{U})=-\nabla p$

with $U$ being the fluid velocity vector, $\rho$ the fluid density, $\mu$ the dynamic viscosity and $p$ the pressure. To restrict the computational domain to a single periodic segment of the channel, the pressure was decomposed as:

$p=p^{*}+\beta \cdot x$ 
where $p^{*}$ is the periodic component of the pressure, $B$ is the average pressure gradient in the channel and $x$ is the local $x$-coordinate.

After obtaining the velocity and pressure fields at steady state, the solute mass concentration in the computed domain was calculated by solving the solute continuity equation:

$\frac{\partial C}{\partial t}+\nabla \cdot(\boldsymbol{U} C)-\nabla \cdot(D \nabla C)=S$

where $D$ is solute mass diffusivity and $S$ is given by

$S=\frac{-D \iint_{A_{m}}\left(\frac{\partial C}{\partial y}\right)_{m} d A}{\iiint_{V}|U| C d V} \cdot|U| \cdot C$

This field represents a mass source, which is used to replace the mass transferred out of the periodic channel segment through a specified membrane area $\left(A_{m}\right)$. Since each channel segment is divided in small control volumes and $\mathrm{S}$ depends on the position $(\mathrm{x}, \mathrm{y}, \mathrm{z})$ inside the channel segment, in our approach, the solute is preferentially re-injected into regions with higher velocity and solute concentration, while the concentration close to membrane surface is almost not affected by such a numerical approach. In such a way, it is possible to solve the continuity equation for an element of fluid that enters in the channel and moves with the fluid average velocity.

The local mass transfer coefficient at each membrane point can be computed as follows:

$k_{c, \text { local }}=\frac{1}{C_{b}-C_{m}}\left(-D \frac{\partial C}{\partial y}\right)_{m}$

where, $C_{b}$ and $C_{m}$ are respectively solute concentration in the bulk and at membrane $(m)$ surface. The DBL thickness was estimated according to the film model from the mass transfer coefficient $\left(k_{c}\right)$ value [35-36]:

$\delta_{D B L}=\frac{D}{k_{c}}$

In order to obtain an average DBL thickness (Figure 2b), the average value of the mass transfer coefficient in the simulated domain was calculated by integration of the local mass transfer coefficient values over the total area of the walls of the channel segment area $(A)$ :

$k_{c}(x)=\frac{1}{A} \int_{A} k_{c, \text { local }} d A$ 
Knowing mass transfer coefficient values allows calculating the RED performance parameters to the different contexts of their applications, this approach has been followed in a number of studies [47-51]. Figure 1 shows a length fraction of a single RED cell with dilute and concentrated compartments formed by anion-exchange (AEM) and cation exchange (CEM) membranes. For ideally permselective membranes, only the respective counter-ions are transported from a concentrated to a dilute stream through the membranes (transport number in the membrane =1). In such a way, the mass flux in the system is only of Coulombic nature [47$48,52]$. For model solutions of $\mathrm{NaCl}$, the solute concentration in the bulk $\left(\mathrm{C}_{\mathrm{b}}\right)$ along a channel can be obtained in the following way:

$C_{b}(x+\Delta x)=C_{b}(x) \pm \frac{i(x) \cdot \Delta x}{F \cdot u \cdot h}$

where $F$ is Faraday constant, $u$ is linear flow velocity, $i$ is the current density per a nominal (flat) membrane area, and $h$ is channel thickness.

Since in RED the current density is much smaller than the limiting current density, the concentration profile in the DBL is linear and, therefore, the solute concentration on the membrane surface in the concentrated compartment $\left(C_{m(c)}\right)$ can be obtained as follows [49, 5355]:

$C_{m(c)}(x)=C_{b(c)}(x) \cdot\left(1-\frac{i^{*}(x) \cdot(T-t) \cdot \delta_{D B L}(x)}{D \cdot F \cdot C_{b(c)}(x)}\right)$

where $D$ is solute mass diffusivity, $\delta_{D B L}$ is diffusion boundary layer thickness and $T$ and $t$ are, respectively, the counter-ion transport number in the membrane and in the solution. Since the current has been previously normalized by the flat membrane area $\left(A_{\text {flat }}\right)$, but at the membrane interface the current density $\left(i^{\star}\right)$ is smaller due to a larger available membrane area created by corrugations $\left(A_{\text {profiled }}\right), i^{*}(x)$ has been accounted as follows (Figure 2 ):

$i^{*}(x)=\frac{i(x) \cdot A_{\text {flat }}}{A_{\text {profiled }}}$

By simplifying that the membrane permselectivity is ideal and the transport numbers of the ions in solution are equal, the concentration polarization close to both, AEM and CEM, surfaces, is simulated as symmetrical $[28,56]$. Therefore, if the hydrodynamic conditions in the dilute and concentrated solutions channels are identical, and the solute mass diffusivity is considered equal in both compartments (for $\mathrm{NaCl}$ solutions within the range of 1-30 $\mathrm{g} / \mathrm{L}$ the differences in mass diffusivity are less than $4 \%$ [10]), the solute concentration on the membrane surface contacting the dilute solution can be calculated as follows: 


$$
C_{m(d)}(x)=C_{b(d)}(x)+\left(C_{b(c)}(x)-C_{m(c)}(x)\right)
$$

Using the extended Debye-Huckel equation to calculate the respective solution activities $(\gamma \cdot C)$ [50], it becomes possible to calculate along the channel the open circuit voltage ( $\mathrm{OCV}$ :

$O C V(x)=2 N \cdot \frac{R \cdot T}{F} \cdot \ln \left(\frac{\gamma_{m, c}(x) \cdot C_{m, c}(x)}{\gamma_{m, d}(x) \cdot C_{m, d}(x)}\right)$

$O C V$ is the RED driving force, $R$ is the universal gas constant, $T$ is the temperature, $\gamma$ is the activity coefficient and $N$ is the number of cell pairs.

The other important parameter is the RED stack internal resistance $\left(R_{i}\right)$, which can be considered as a sum of ohmic and diffusion boundary layer resistances [7, 12-13, 27, 43, 47]. Due to variation of the solute concentration along the channel, the internal electric resistance correspondingly depends on the position along the channel. The ohmic resistance is composed by the sum of the resistances of cation-exchange $\left(R_{C E M}\right)$, anion-exchange $\left(R_{A E M}\right)$ membranes, bulk solutions $\left(h_{b} / \kappa_{b}\right)$ and electrodes $\left(R_{e l}\right)$ :

$R_{\text {ohmic }}(x)=N \cdot\left(\frac{R_{C E M}}{1-f}+\frac{R_{A E M}}{1-f}+\frac{h_{b, c}(x)}{\varepsilon \cdot \kappa_{b, c}(x)}+\frac{h_{b, d}(x)}{\varepsilon \cdot \kappa_{b, d}(x)}\right)+R_{e l}$

where $K$ is the solution conductivity, $f$ is the fraction of membrane area covered by nonconductive spacers, $\varepsilon$ is the spacers porosity (if present) and $h_{b}$ corresponds to equivalent intermembrane distance not occupied by DBLs (Figure 2c). The electrodes resistance can be ignored if a big number of cell pairs is considered [48].

The resistance due to the $\mathrm{DBL}\left(R_{D B L}\right)$ can be accounted for as follows [10]:

$R_{D B L}(x)=N \cdot\left(2 \frac{\delta_{D B L}(x)}{\kappa_{D B L, c}(x)}+2 \frac{\delta_{D B L}(x)}{\kappa_{D B L, d}(x)}\right)$

Since the solute concentration profile across the DBL is linear [49, 53-55], as the DBL solution conductivity we have considered an average value of the solutions conductivity in the bulk and on the membrane surface.

The gross power density $\left(P_{\text {gross }}\right)$, when an external load resistance $(R e)$ is applied, can be obtained as follows:

$P_{\text {gross }}(x)=i^{2}(x) \cdot R_{e}(x)$

The value of $i(\mathrm{x})$ is adjusted by minimization of the least squares between the OCV values calculated by equations 16 and 20 : 
The maximum value of gross power density, at $50 \%$ efficiency of energy extraction, is achieved when the external load resistance has the same value as the internal stack resistance $[5,8,44$, 57-60]. For such a case:

$P_{\text {gross }}(x)=\frac{O C V(x)^{2}}{4 \cdot R_{i}(x)}$

In practical terms, this means that a stack with infinitely segmented electrodes is considered [44]. In order to obtain the value for a whole stack, it is necessary to integrate the local values along the channels length $(L)$ :

$P_{\operatorname{gross}(L)}=\frac{\int_{0}^{x=L} P_{\text {gross }}(x) d x}{L}$

Thus, it becomes possible to calculate the net power density $\left(P_{\text {net }}\right)$ of a RED stack, which consists in a trade-off between the generated (gross) power and the power consumed for pumping the solutions ( $\left.P_{\text {pumping }}\right)$ :

$P_{\text {net density }}=P_{\text {gross density }}-\frac{P_{\text {pumping }}}{2 \cdot N \cdot A_{\text {flat }}}$

The power spent for pumping depends on the feed solution flow rate $(Q)$ and the total pressure drop $\left(\Delta p_{t}\right)$ between the stack inlet and outlet [61]:

$P_{\text {pumping }}=2 \cdot\left(\Delta p_{t} \cdot Q\right)$

The factor 2 appears because there are two saline solutions which are pumped, the dilute and the concentrated one. Based on previous studies [7, 12, 38, 61] we have considered for all simulated domains that the total pressure drop $\left(\Delta p_{t}\right)$ in a RED stack is:

$\Delta p_{t}=\Delta p_{\text {channel }}+12 \cdot \Delta p_{10 \text { cm empty channel }(h=0.5 \mathrm{~mm})}$

where the second term accounts for the partial pressure drop in manifolds. The second term in eq. 25 remains constant in all simulations, as the pressure drop in the manifolds does not depend on the working channels shape [61]. The important influence of manifolds on RED stack performance has been recognized [38, 61]; however, optimization of the manifolds system distribution is beyond the scope of the present study. 


\section{Methodology}

\subsection{CFD Numerical methods}

The open-source OpenFOAM software package, version 2.3.0 [62], was used to simulate the flow patterns and mass transfer in a RED channel formed by two profiled membranes.

Equations 4-5 and 7 were solved by the transient pressure-implicit PIMPLE (merged PISOSIMPLE) algorithm with 3 outer correctors for inter-equation coupling in the pressure-velocity system until the value of average velocity in the channel reached the specified goal while the value of $\beta$ (eq. 6) was adjusted [62]. Time discretization was achieved by a second order backward Euler scheme and a $4^{\text {th }}$ order Gauss scheme was used for spatial discretization of the solute continuity equation. The time step was lower than $1 \mathrm{~ms}$ in order to guarantee temporal accuracy and numerical stability. The simulations were processed on a four-node cluster (1.9 $\mathrm{GHz}$ CPU, $512 \mathrm{MB}$ RAM/CPU) and the computational time varied from few hours up to a couple of days, depending on the simulated domain complexity. A preliminary mesh independence study was used to select the appropriate mesh for each case.

To draw all structures investigated by CFD, SolidWorks 2012 software was used to create $s t$ files with the membrane design. The computational grid was generated from them by blockMesh and snappyHexMesh OpenFOAM grid generation utilities. The created grid had a block-structure, in which a single block had an average volume of $4.0 \cdot 10^{-6} \mathrm{~mm}^{3}$. Near the channel walls the grid was refined to resolve accurately the concentration boundary layers.

\subsection{Channels shape}

The net power density has been calculated for $\mathrm{NaCl}$ solutions of 1 and $30 \mathrm{~g} / \mathrm{L}$ as inlet saline streams, for an average linear flow velocity inside the channel of $0.5,1.0,1.5$ and $2.0 \mathrm{~cm} / \mathrm{s}$, respectively. The physical parameters used in the simulations are summarized in Table 1.

Table 1. Physical parameters used in simulations.

\begin{tabular}{ll}
\hline Parameter & Value \\
\hline$\mu(\mathrm{NaCl})$ & $0.00103 \mathrm{~kg} /(\mathrm{m} \cdot \mathrm{s})$ \\
$\rho(\mathrm{NaCl})$ & $998.2\left(\mathrm{~kg} / \mathrm{m}^{3}\right)$ \\
$D_{\mathrm{NaCl}}$ & $1.51 \cdot 10^{-9}\left(\mathrm{~m}^{2} / \mathrm{s}\right)$ \\
$R_{C E M}=R_{A E M}$ & $7.5\left(\Omega \cdot \mathrm{cm}^{2}\right)$ \\
$T$ & $293.15 \mathrm{~K}$ \\
$R$ & $8.314 \mathrm{~J} /(\mathrm{mol} \cdot \mathrm{K})$ \\
$F$ & $96485.34 \mathrm{C} / \mathrm{mol}$ \\
\hline
\end{tabular}


The considered membrane area resistance is that of heterogeneous Ralex membranes [63], transformed into profiled membranes as they are mechanically rather stable. From a profiled membrane manufacturing point of view, the non-profiled membrane part should remain at least $0.2 \mathrm{~mm}$ thick in order to not start waving [25].

The initial simulations were done in two-dimensional space (2D), since it has been reported that the greatest mass transport improvement is reached for a flow directed at an angle of $90^{\circ}$ to the corrugated membranes [18, 64], and that in channels with spacers, the flow structure is mainly determined by the spacer transverse filaments [35]. Given the simplicity of performing such simulations, twenty two different designs were initially compared (see, Supplementary material).

Since in such an arrangement the membranes reliefs must not touch each other, as this would obstruct the flow in the channel, a supporting frame is required to maintain the intermembrane distance. Knowing that for existing profiled membranes the open area is of $83 \%$ [7], we made an educated guess that this frame should cover $20 \%$ of the membrane area.

The initial dimensions of the 2D simulated corrugations have been based on those of already existing profiled membranes, with corrugation width $\left(w_{c}\right)$, height $\left(h_{c}\right)$ and distance between corrugations $\left(d_{c}\right)$ of $0.2 \mathrm{~mm}, 0.1 \mathrm{~mm}$ and $1 \mathrm{~mm}$, respectively $[7,12,25]$. The channel thickness was chosen to be $0.5 \mathrm{~mm}$. After identifying the most promising geometries, by comparing the net power densities ratio $(\theta)$, the corrugation height and the distance between two consecutive corrugations were optimized in terms of estimated net power density.

Based on the conclusions drawn from the $2 \mathrm{D}$ simulations results, $3 \mathrm{D}$ simulations were performed for two cases. The first one is known as "pillars" and has already been applied for power generation by RED $[25,28]$, while the second one has been inspired by staggered herringbone groves of fluidic mixing micro-devices [65-66]. For pillars, the dimensions are of the profiled membranes which were already fabricated [25], while for chevrons the dimensions were chosen in order to assure that the equivalent height of both structures is similar ( 0.411 and $0.417 \mathrm{~mm}$ for channels formed by pillars and chevrons, respectively). 

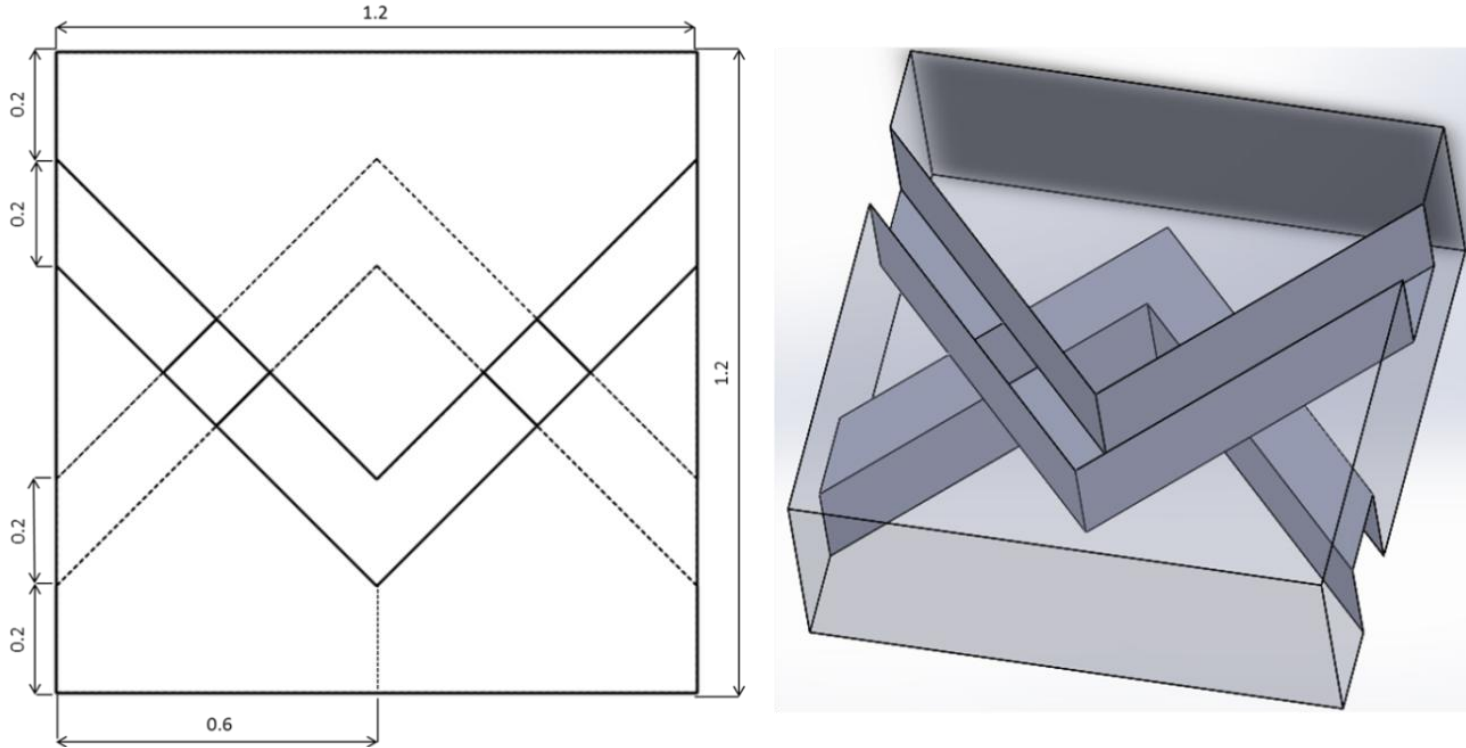

Figure 3. Dimensions of a repeated geometry segment of a channel with chevron corrugations used for CFD calculations.

Figure 3 shows the dimensions of a repetitive segment of the channel with chevron corrugations. This structure is similar to a design of a diamond-shape spacer, and therefore is expected to provide fully developed mass transfer conditions within the whole channel, even at low Reynolds numbers [67].

Based on the mass transfer coefficient values obtained at the simulated linear flow velocities range, dimensionless empirical mass transfer correlations $\left(S h=a R e^{b} S c^{0.33}\right)$ were obtained for pillar and chevron-like structures by adjusting the values of $a$ and $b$. The Schmidt number ( $S c)$ exponent is commonly set as $0.33[30,32,41,55]$ and was assumed as such herein. The Sherwood (Sh), Reynolds ( $R e$ ) and Schmidt (Sc) numbers were calculated as follows:

$S h=\frac{k_{c} \cdot h_{e q}}{D}$

$R e=\frac{\rho \cdot u \cdot h_{e q}}{\mu}$

$S c=\frac{\mu}{\rho \cdot D}$

In order to compare the performance of the corrugations with non-conductive and conductive spacers, we calculated the net power density for such stacks, maintaining the same intermembrane distance and parameters values summarized in Table 1. The shadow effect of non-conductive spacers was assumed to be $50 \%$ and both spacers porosities equal to 0.775 [61]. The mass transfer coefficient for channels with spacers was calculated by a previously developed and validated mass transfer correlation $\left(S h=0.29 \mathrm{Re}^{0.5} \mathrm{Sc}^{0.33}\right)[10]$. The pressure drop 
in the channel was obtained by the Darcy-Weisbach equation with a modified hydraulic diameter, which accounts for the spacer influence on pressure drop [61]:

$d_{c h}=\frac{4 \cdot \varepsilon}{\frac{2}{h}+(1-\varepsilon) \cdot \frac{8}{h}}$

\section{Results and discussion}

\subsection{D CFD simulations}

As mentioned in Section 3.2, the available membrane area strongly affects the obtainable net power density. Therefore preliminary studies (see Supplementary material) were performed to find which corrugation geometries improve more significantly the obtainable net power density through their effects on mass transfer and on pressure drop.

A direct comparison of net power densities obtained with the studied corrugations shows that the highest net power density values were obtained for corrugations providing higher membrane surface area, even though pressure drop also increased in such cases. However, the highest difference in net power density among the cases studied did not exceed $7 \%$, since the differences in available membrane area are actually small. The net power density shows to be sensitive to mass transfer coefficient and pressure drop values obtained by CFD, as for different corrugations, but with the same surface area, i.e., for the same equivalent channel height, the calculated net power density values were different between the cases, which opens space for corrugation shape optimization.

Since the distance between two consecutive corrugations and their height can be varied and, therefore, the membrane area could be increased for any of the studied corrugations, what is important to know is which geometry has the highest potential to increase the net power density due to its effect on mass transfer coefficient and on pressure drop. Therefore, we calculated the net power density ratios as defined by equation 3 . The corrugation shapes more suitable for optimization are those with a higher ratio, since, in such cases, a corrugation increases more significantly the obtainable net power density only due to its shape. In this study, corrugations " $A$ " and " $C$ " presented the highest net power density ratios for mirror and diagonal arrangements, at linear flow velocities of 0.5 and $2.0 \mathrm{~cm} / \mathrm{s}$, respectively, and, therefore were the most promising structures to be investigated (see Supplementary material).

However, it was found, for both arrangements, that the only meaningful advantage of using transversal corrugation was a reduction of the spacer shadow effect comparatively to the design with non-conductive spacers. The optimal geometry based on $\theta$ (if the influence of the available membrane area on the ohmic resistance is ignored) tends to approximate to that of a flat (non- 
corrugated) membrane, as the trade-off between mass transfer increase and pressure drop increase is not favorable when the corrugations dimensions increase. A discussion on the $2 \mathrm{D}$ simulations results obtained can be found in Supplementary material.

\subsection{Pillar and chevron corrugations (3D CFD simulations)}

\subsubsection{Mass transfer coefficients and pressure drop}

Since 2D simulated corrugations did not promoted an effective fluid mixture close to membranes surfaces, more complex geometries must be investigated in order to induce transverse flow instabilities. Such structures require representation in a 3D space. Membrane corrugations in the form of pillars are one of the possibilities that have been already suggested for RED [25]. However, such corrugations can lead to creation of stagnant zones upstream to the structures. In these stagnant regions, particle deposition and biofilm formation may occur $[28,68]$. 3D simulations performed by us for a pillar geometry (not shown) confirmed the existence of such stagnant regions upstream to the corrugation.

Therefore, inspired by microfluidic mixture devices [65-66], in which the flow is laminar, a herringbone type of corrugations was investigated. Since the herringbones grove depth strongly influences the mixing efficiency, while the flow attack angle does not [65-66], when groves exist on the two faces forming a channel, chaotic flows are induced and the mixing channel length is reduced [69]. Arrangement of symmetric herringbones on both faces of a channel is known as "chevrons" in the microfluidic devices related literature [70]. Herein, this type of corrugation was simulated for the first time in the context of a RED application.

Figure 4 presents the simulated mass transfer coefficient values of on the membrane surface for chevron channels at linear flow velocities of $0.5 \mathrm{~cm} / \mathrm{s}$ and $2.0 \mathrm{~cm} / \mathrm{s}$ when the solute concentration profile is fully developed. 
a)

b)

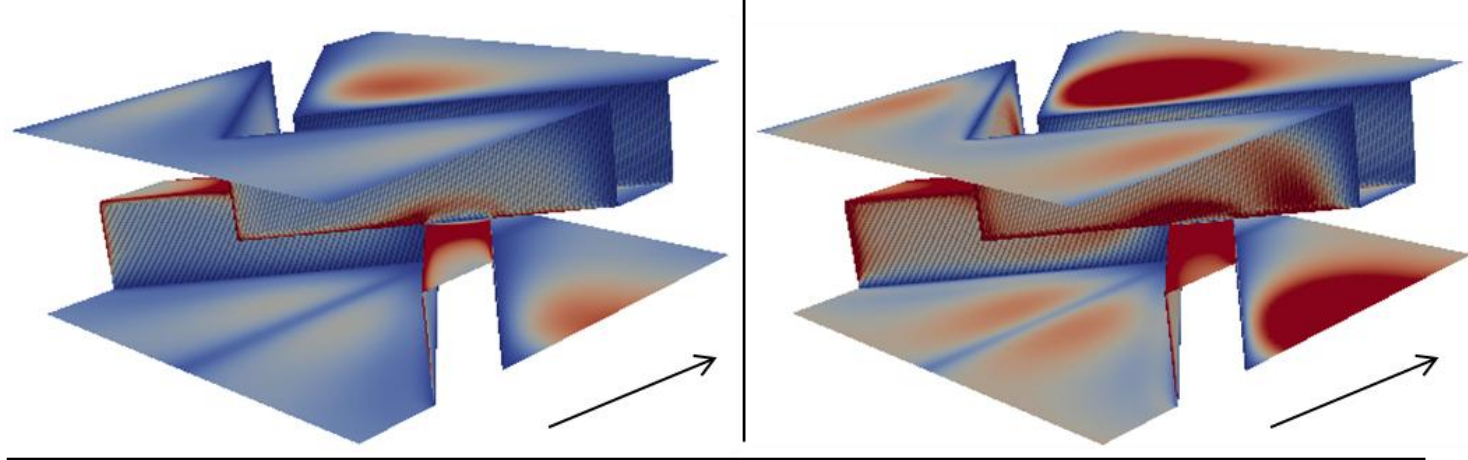

Figure 4. Maps of mass transfer coefficient in channels formed by membranes with chevron corrugations at two average linear flow rates: a) $0.5 \mathrm{~cm} / \mathrm{s}$, b) $2.0 \mathrm{~cm} / \mathrm{s}$.

As expected, the mass transfer coefficient values are lower at a lower linear flow velocity; however, in both cases the fluid flow distribution is similar. The main advantage of using the chevron design appears to be related to high local mass transfer coefficient values upstream to the chevron, where usually there are issues associated with flow dead zones. In this case, the only dead zone, which extends through the channel length, was found to be that located upstream to the chevron tip, and in such a way it occupies only a very small channel volume.

Figure 5 shows a comparison between pillar and chevron corrugations in terms of mass transfer coefficients and pressure drop within an identical linear flow velocity range. 


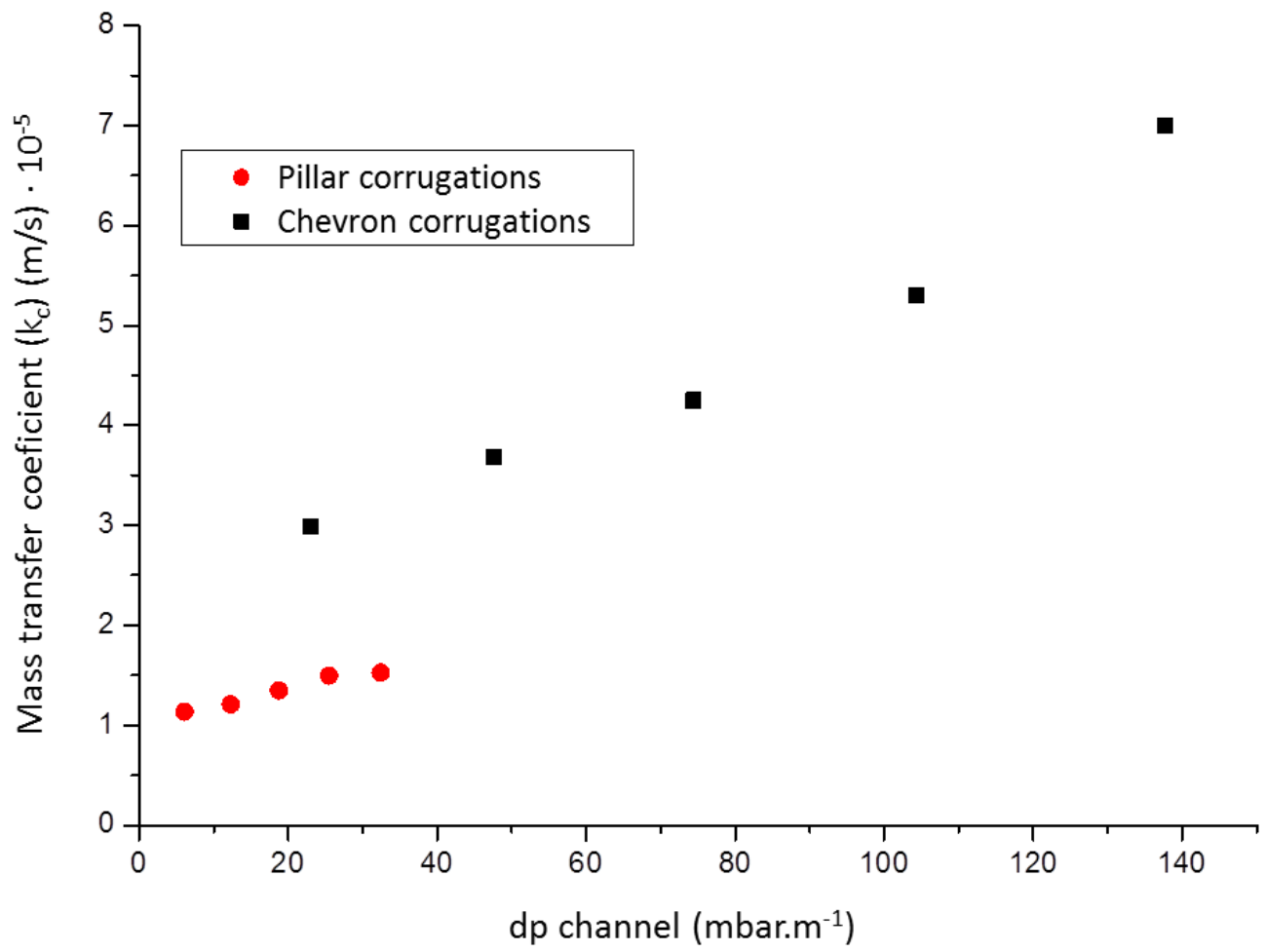

Figure 5. Representation of the average mass transfer coefficient at fully developed concentration profile in function of pressure drop for a linear flow velocity range between 0.5 $\mathrm{cm} / \mathrm{s}$ and $2.5 \mathrm{~cm} / \mathrm{s}$.

Within the studied linear flow velocities range $(0.5 \mathrm{~cm} / \mathrm{s}-2.5 \mathrm{~cm} / \mathrm{s})$, the mass transfer coefficient was found to be always higher for the design with chevron corrugations than for the design with pillars. The respective dimensionless empirical mass transfer correlations were:

- $S h=0.53 R e^{0.59} S c^{0.33}$, for chevron corrugations, and

$-S h=0.30 R e^{0.20} S c^{0.33}$, for pillar corrugations.

As it can be seen (Figure 5), for the same pressure drop, the mass transfer coefficient is higher for chevron corrugations, what could indicate that utilization of chevrons leads to a better fluid dynamics in the so formed channels. However, as a higher pressure drop was found at the same linear flow velocity for the chevron structures, the enhancement of mass transfer comes at an increased energy demand penalty, which may outweigh its benefits in terms of the power gained. Therefore a more detailed study on the obtainable net power densities is required.

\subsubsection{Net power density}

Figures $6 \mathrm{a}$ and $6 \mathrm{~b}$ present the overall net power densities values for pillar and chevron structures, respectively, for channels with different lengths. In stacks with very short channels, and therefore small membrane area, the net power density departs from negative values. That 
is caused by pressure drops in the stack flow distribution system (due to branches and in distribution ducts), which do not depend on channel length [61]. Therefore, when the power spent for pumping is normalized by the membrane area (eq. 23) it becomes much bigger than the obtained gross power density.
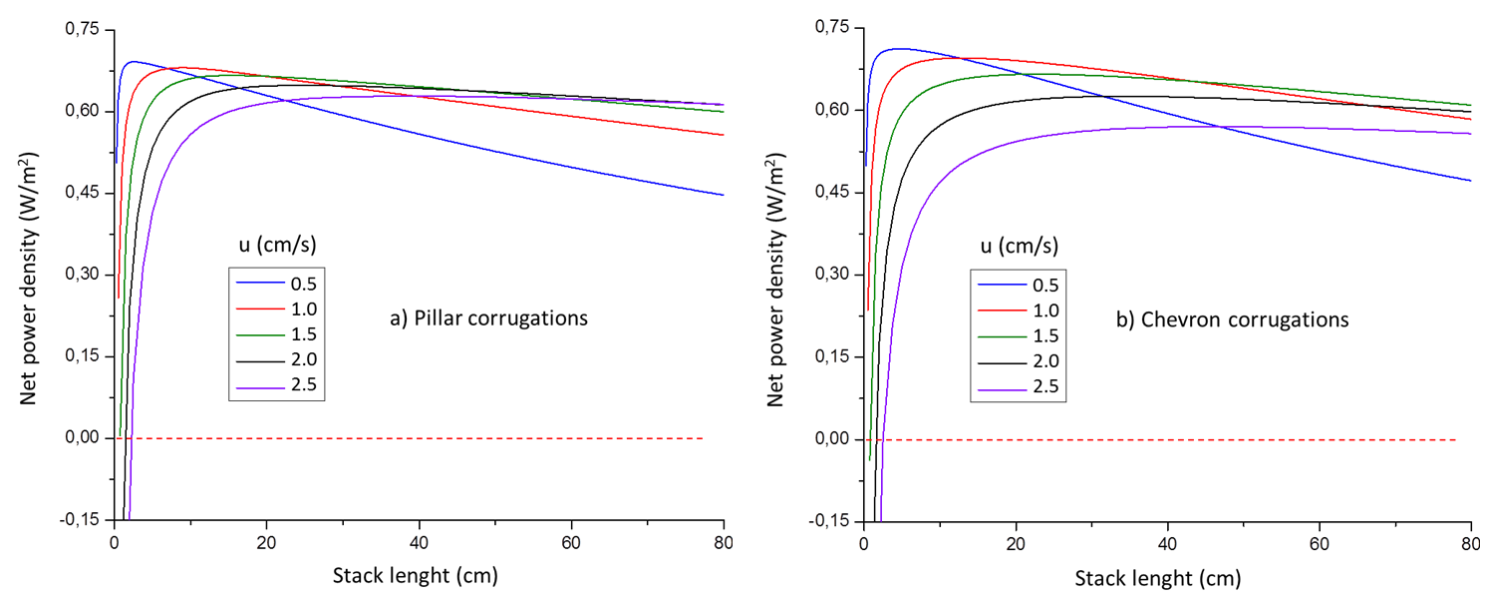

Figure 6. Simulated net power density $\left(\mathrm{W} / \mathrm{m}^{2}\right)$ in stacks with a) pillar and b) chevron corrugations at different linear flow velocities $(\mathrm{cm} / \mathrm{s})$ for variable stacks' length.

As the channel length and the membrane area increase, the net power density becomes positive and reaches its maximum value. The decrease in the net power density afterwards is caused by a decrease in the potential difference along the channel, since the ions are transported from concentrated to dilute saline stream compartments (Appendix A). The maximal net power density values are higher for smaller linear flow velocities and smaller channels lengths since, for the same average potential difference, the pressure drop in the channels is smaller. As the channel length increases, in order to keep the potential difference high along the channel length, the linear flow velocity must also increase, what leads to an increase in the pressure drop, especially in the manifolds [61], and a decrease of the obtainable maximal net power density values.

The solutions residence time in the channels at which the maximal net power densities are obtained is not the same for the different velocities. For example, for a chevron geometry, the optimum fluid residence time is 7.5 seconds for a linear flow velocity of $0.5 \mathrm{~cm} / \mathrm{s}$, and 13 seconds for a linear flow velocity of $2.0 \mathrm{~cm} / \mathrm{s}$. This difference is caused by more pronounced flow entrance effects on mass transfer as the linear flow velocity increases [10].

In terms of the obtainable net power density, the maximal values were higher for the chevron design up to a linear flow velocity of $1.5 \mathrm{~cm} / \mathrm{s}$. This means that chevron-like corrugations perform better than pillar corrugations under the conditions more indicated for power generation, i.e. a stack with short channels, since their utilization will generate more net power. 
Above $1.5 \mathrm{~cm} / \mathrm{s}$, the higher pressure drop caused by chevron-like corrugations limits their utilization.

One of the advantages of utilizing profiled membranes has been reported to be a pressure drop reduction comparatively to the case of using spacers (conductive and non-conductive) [12]. Nevertheless, since the simulations demonstrate that chevron structures performed better than pillar forms, which in turn were proven to be better than spacers [25], the higher pressure drop offered by chevron corrugations does not seem impeditive, if the linear velocity range (Table 2) is wisely chosen.

Table 2. Comparison of RED stacks with chevron and pillar corrugations and with conductive and non-conductive spacers.

\begin{tabular}{c|ccc|ccc|ccc}
\hline $\mathbf{u}$ & \multicolumn{2}{|c|}{ Max. $P_{\text {net }}$ Density $\left(\mathrm{W} / \mathrm{m}^{2}\right)$} & \multicolumn{3}{|c|}{$\mathrm{k}_{\mathrm{c}}(\mathrm{m} / \mathrm{s}) \cdot 10^{\left.-5 *^{*}\right)}$} & \multicolumn{3}{|c}{$\mathrm{dp}$ channel (mbar/m) } \\
$\mathbf{( \mathbf { c m } / \mathbf { s } )}$ & Pillar & Chevron & $\begin{array}{c}\text { (Non) } \\
\text { Conductive } \\
\text { Spacer }\end{array}$ & Pillar & Chevron & $\begin{array}{c}\text { w/ } \\
\text { Spacer }\end{array}$ & Pillar & Chevron & $\begin{array}{c}\text { w/ } \\
\text { Spacer }\end{array}$ \\
\hline $\mathbf{0 . 5}$ & 0.69 & 0.71 & $(0.41) 0.58$ & 1.14 & 2.99 & 1.30 & 6.08 & 23.07 & 14.47 \\
$\mathbf{1 . 0}$ & 0.68 & 0.70 & $(0.40) 0.59$ & 1.21 & 3.68 & 1.83 & 12.31 & 47.56 & 28.94 \\
$\mathbf{1 . 5}$ & 0.67 & 0.67 & $(0.38) 0.57$ & 1.35 & 4.25 & 2.25 & 18.76 & 74.44 & 43.40 \\
$\mathbf{2 . 0}$ & 0.65 & 0.63 & $(0.35) 0.55$ & 1.49 & 5.30 & 2.60 & 25.48 & 104.32 & 57.87 \\
$\mathbf{2 . 5}$ & 0.63 & 0.57 & $(0.32) 0.52$ & 1.53 & 7.00 & 2.90 & 32.45 & 137.68 & 72.34 \\
\hline
\end{tabular}

$\left({ }^{*}\right)$ Values obtained for the region of a fully developed solute concentration profile (i.e. without flow entrance effects influence on mass transfer.

With the proposed chevron-like design, at a linear velocity range of $0.5-1.5 \mathrm{~cm} / \mathrm{s}$, the pressure drop is $\sim 1.6-1.7$ times higher comparatively to utilization of spacers, but also a higher increase in mass transfer coefficient $(\sim 2.3-1.9 x)$ is obtained. This may indicate that the energy spent for reducing the diffusion boundary layer thickness is applied where it is precisely needed (in the vicinity of the membrane surfaces), opposite to the case of spacers, which mainly promote bulk solution mixing. In such a way, chevron structures allow for a more significant increase in the mass transfer coefficient.

In section 2.1, the parameter $\theta$ was defined for comparing the performance of different corrugations in terms of obtainable net power density through dividing the net power density for a stack with corrugations/spacers by the net power density obtainable in a hypothetical stack with empty channels. The equivalent thickness of both channels was considered to be the same, what allows for excluding the influence of the ohmic resistance on the obtainable net power density and for comparing the effects of pressure drop and mass transfer coefficient.

Figure 7 shows the value of this ratio for the simulated corrugations and spacers using maximal obtainable net power density values at each linear flow velocity. Since the membrane price is currently the limiting factor for RED implementation, we believe that it is preferential to compare the stacks between them under correspondingly optimized conditions, at which the membrane 
area is most effectively used. Such a choice means that the channel length, at which the maximal net power density is obtained, is not the same at different channels configurations, as can be seen in Figure 6.

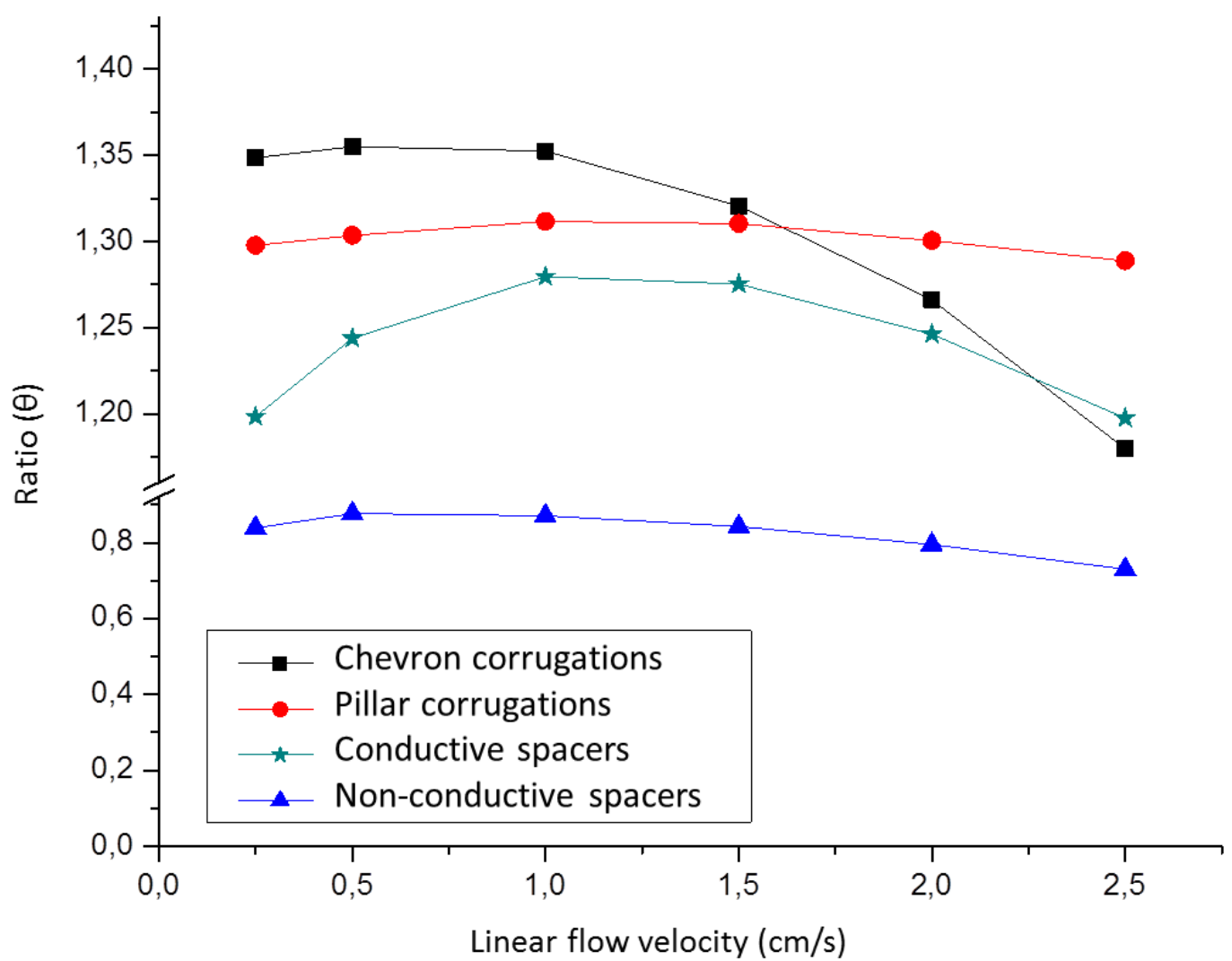

Figure 7. Comparison of the $\theta$ parameter values obtained for stacks with profiled membranes (Pillar and Chevron) and stacks with spacers (conductive and non-conductive) with the respective channels' length optimized in terms of the maximal obtainable net power density (eq. $3)$.

As seen in Figure 7, the ratios are always higher than 1, except for a stack with non-conductive spacers. Moreover, the ratio for channels with corrugated membranes is higher than for a stack with conductive spacers. Also, since the values are higher than 1, this means that the shape of the corrugation had also improved the fluid dynamics, besides increasing the available membrane area, which it is an advantage relatively to corrugations which are perpendicular to the fluid flow.

The chevron corrugations proposed show that the highest improvement of stack performance and their highest efficiency is for linear velocities between $0.5 \mathrm{~cm} / \mathrm{s}$ and $1.5 \mathrm{~cm} / \mathrm{s}$. For higher linear velocities, the use of chevron structures becomes less efficient. Curiously, since the chevron design is somehow similar to the design of a diamond-shape spacer, but with an 
advantage of a forced fluid transport upstream to the corrugations, the shape of the $(\theta)$ ratio curves for chevron and diamond-type spacers is very similar (Fig. 7).

It is also important to consider some practical issues when the choice of the corrugations and channels dimensions is done. As the final objective of RED is to take advantage of expected realizable global salinity gradient potential, due to rivers discharge, which is estimated to be close to 1 TW [4, 71], large membrane areas must be used. Despite the fact that shorter channels allow for achievement of higher net power density values, from a practical point of view, utilization of longer channels and, therefore, higher linear flow velocities, could be more advisable. Under such conditions, for example for $30 \mathrm{~cm}$ long channels the optimum linear flow velocity for chevron configuration is around $1.0 \mathrm{~cm} / \mathrm{s}$, while for pillars is around $1.5 \mathrm{~cm} / \mathrm{s}$ (Graphical abstract). Therefore, we anticipate that the developed chevron corrugations could improve the RED process economy by reducing the feed flowrate of the two solutions of different salinity.

\section{Outlook}

The results of this study support the idea that the use of non-conductive spacers, which increase the ohmic resistance and can create regions prone to fouling in their knits [26, 72], should be avoided. Utilization of profiled membranes, with the proposed chevron corrugation shape, offers an appropriate trade-off between mass transfer and pressure drop, besides reducing the channels dead flow zones and increasing the available membrane area for ion transport. However, under currently realistic conditions for industrial-scale power generation, e.g., channels thickness of $0.5 \mathrm{~mm}$ (in order to avoid channels clogging) and chevron-like profiled membranes created from heterogeneous ion-exchange membranes (with a membrane area resistance of $7.5 \Omega \mathrm{cm}^{2}$ ), the maximal expected net power density value (at a linear flow velocity of $0.5 \mathrm{~cm} / \mathrm{s}$ ) is $0.71 \mathrm{~W} / \mathrm{m}^{2}$.

Nevertheless, for chevron-like structures and the same parameters as in Table 1, but assuming a hypothetic profiled membrane area resistance of $1 \Omega \mathrm{cm}^{2}$, the net power density values can be close to $1.15 \mathrm{~W} / \mathrm{m}^{2}$. If a free or cheap heat source could be found to increase the solutions temperature from $20^{\circ} \mathrm{C}$ to $40^{\circ} \mathrm{C}$, the value of the net power density can additionally raise up to $1.3 \mathrm{~W} / \mathrm{m}^{2}$. Therefore, development of membranes with a low area electric resistance, but still thick enough to allow creating corrugations on their surfaces, is of an obvious interest. Even a higher increase in net power density could be achieved if, at the same time, the thickness of the channels can be also reduced. Based on the developed mass-transfer correlation, the obtainable net power density could be as high as $3.7\left(\right.$ at $20^{\circ} \mathrm{C}$ ) and $4.2\left(\right.$ at $40^{\circ} \mathrm{C}$ ) W/m with chevron structures and the channel equivalent thickness of $0.1 \mathrm{~mm}$. However, utilization of such thin channels will most probably require extensive water pretreatment in order to remove possible foulants (sands, clays, humic compounds, etc.) from the water streams [26, 72-73]. 
The costs associated to such pretreatment have been reported to be eventually higher than the solutions pumping associated costs [74]. Therefore, further studies are needed.

Also, as a general rule, it can be stated that channels should be as short as possible, in order to benefit from the flow entrance effect on mass transfer [10]. At the same time, the channels cannot be too short in order to avoid a situation, at which the power spent for solutions pumping and required to overcome the partial pressure drops in the stack manifolds and branches (which are independent from the channel length) exceeds the generated power [61]. As the pressure drop in the manifolds becomes dominant when the channels are shorter, the feedwater distribution system becomes very important and should be optimized.

For designing new and improved feedwater distribution systems, CFD tools can be used, as the main objective passes through minimization of the pressure drop, which can be accounted for by the mass continuity and Navier-Stokes equations. An alternative to modification of the feedwater distribution system geometry could pass through changing the stack design from a plate-and-frame type to a tubular or a radial membrane arrangement. There are a number of designs explored in the field of heat exchangers and microfluidic devices, which may serve as sources of inspiration [75].

\section{Conclusions}

In the present work, we have simulated the net power density of RED stacks with different channel arrangement. Profiled membranes with corrugations perpendicular to flow as well as chevron and pillar structures were investigated in detail. The results were compared with the performance of RED stacks with conductive and non-conductive spacers.

Utilization of profiled membranes and conductive spacers present the already known advantage of eliminating the shadow effect when non-conductive spacers are used. In terms of fluid dynamic effects on net power density, perpendicular corrugations do not enhance the stack performance, but still lead to a net power density increase due to the increase of the available membrane area for counter-ion transport.

The chevron and pillar structures lead to higher performances, in terms of the fluid dynamics and net power density, than conductive spacers, which may be an indication that development and utilization of profiled membranes is advantageous. Also, in such a way, lower quantity of expensive and conductive material is used, since the membranes self-maintain the channel compartment thickness.

Simulations of chevron structures show the highest net power density values and the best compromise between mass transfer coefficient and pressure drop increase. Moreover, it is 
expected that due to the very specific fluid pathway, the channels with chevron corrugation will be less prone to fouling. Also, in order to grant a maximal net power density for a given stack length, the linear flow velocity is lower when chevron corrugations are applied, which, for industrial size equipment, may represent economic advantages since smaller volumes of water must be pretreated.

The simulated chevron structures still need to be experimentally validated, as well as their geometry parameters should be optimized for RED application. Moreover, since we found that chevron structures do not only generate more power when used in RED stacks, but also represent the best compromise between mass transfer and pressure drop, they also should also be rather promising for other electromembrane processes.

\section{Acknowledgments}

Sylwin Pawlowski would like to acknowledge the Fundação para a Ciência e a Tecnologia (FCT), Lisbon, Portugal, for his PhD research grant SFRH/BD/68649/2010. The financial support of this work by FCT through Project Pest-C/EQB/LA0006/2013 is also gratefully acknowledged.

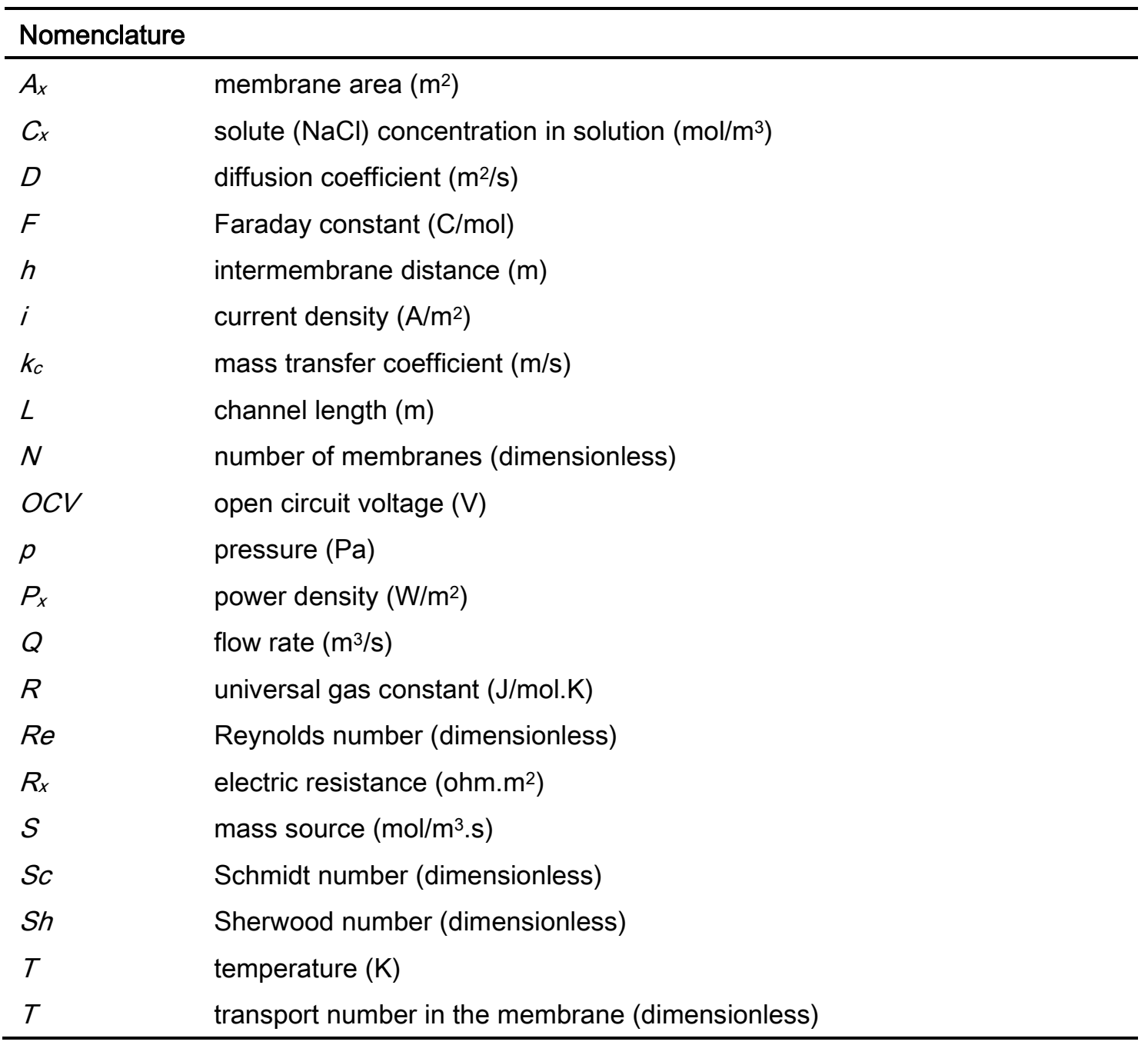


transport number in the solution (dimensionless)

fluid velocity vector $(\mathrm{m} / \mathrm{s})$

fluid linear flow velocity in the channel $(\mathrm{m} / \mathrm{s})$

volume $\left(\mathrm{m}^{3}\right)$

Coordinate in the direction of the channel length

Coordinate in the direction of the channel thickness

Coordinate in the direction of the channel width

"shadow" factor (dimensionless)

diffusion boundary layer (DBL) thickness $(m)$

spacer porosity (dimensionless)

solution conductivity $(\mathrm{S} / \mathrm{m})$

$\kappa_{s o l}$

fluid density $\left(\mathrm{kg} / \mathrm{m}^{3}\right)$

activity coefficient (dimensionless)

\section{Appendix A}

The final goal of the performed simulation was to obtain the net power density values. In order to obtain these values, it was necessary to simulate the solute concentration profiles along the channel, and then to calculate the local electric potential difference and resistances values.

Herein, the case for channels with chevron structures for a linear flow velocity of $0.5 \mathrm{~cm} / \mathrm{s}$ is presented. The respective curve for net power density can be seen in Figure 6b. 


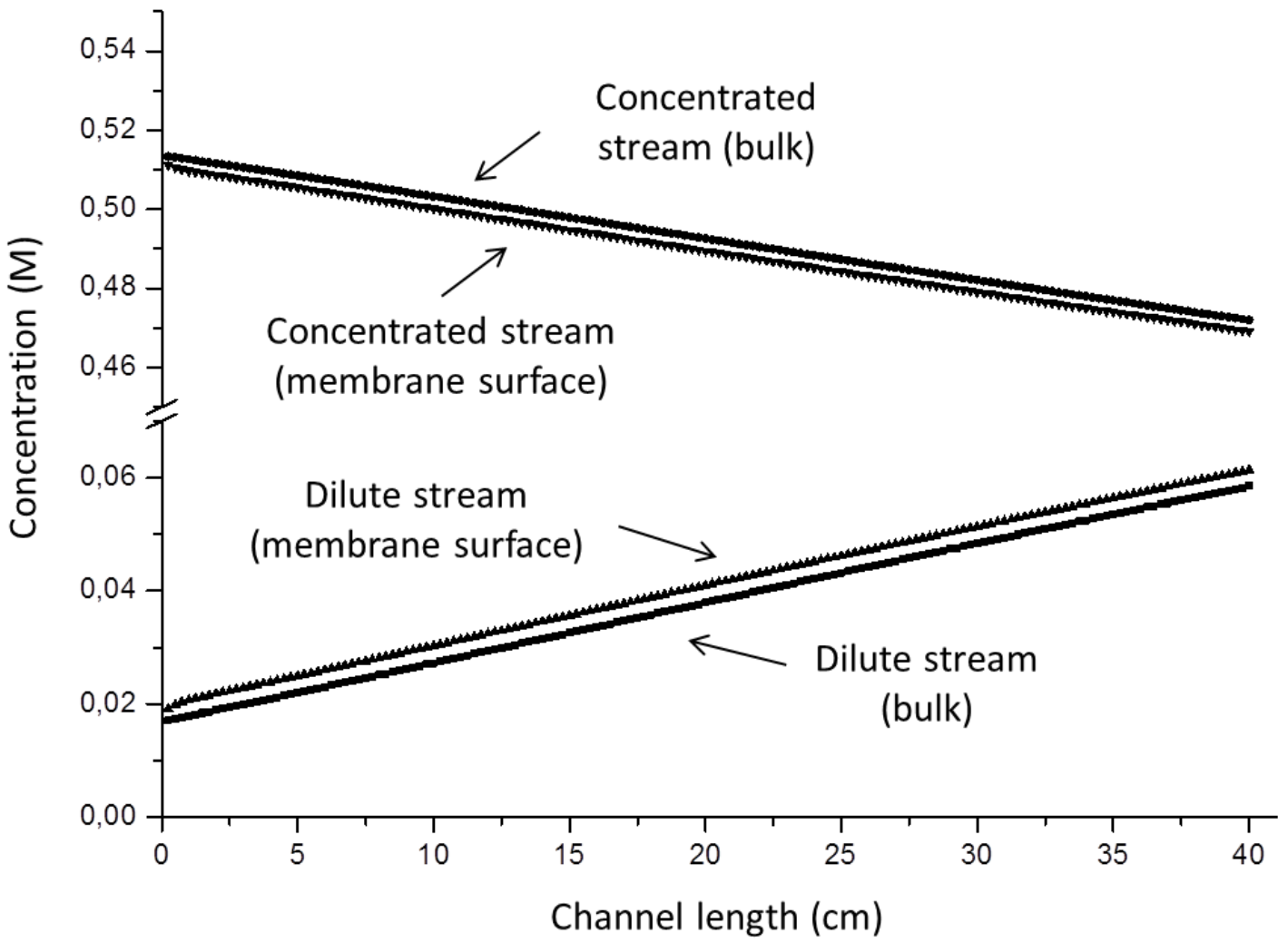

Figure A.1. Solute $(\mathrm{NaCl})$ concentration profiles in dilute and concentrated streams channels in the bulk and on the membrane surfaces.

Figure A.1 shows the profile of solute concentrations in the dilute and concentrated channels. As can be seen, in the dilute saline stream compartment the concentration increases along the channel length, while in the concentrated saline stream compartment the opposite trend is observed. This is due to the transport of ions from the concentrated to the dilute solution compartment during the RED process.

Figure A.2 presents the values of the most significant resistances in a RED stack, besides the resistance of the membranes (set at $7.5 \Omega . \mathrm{cm}^{2}$ ). 


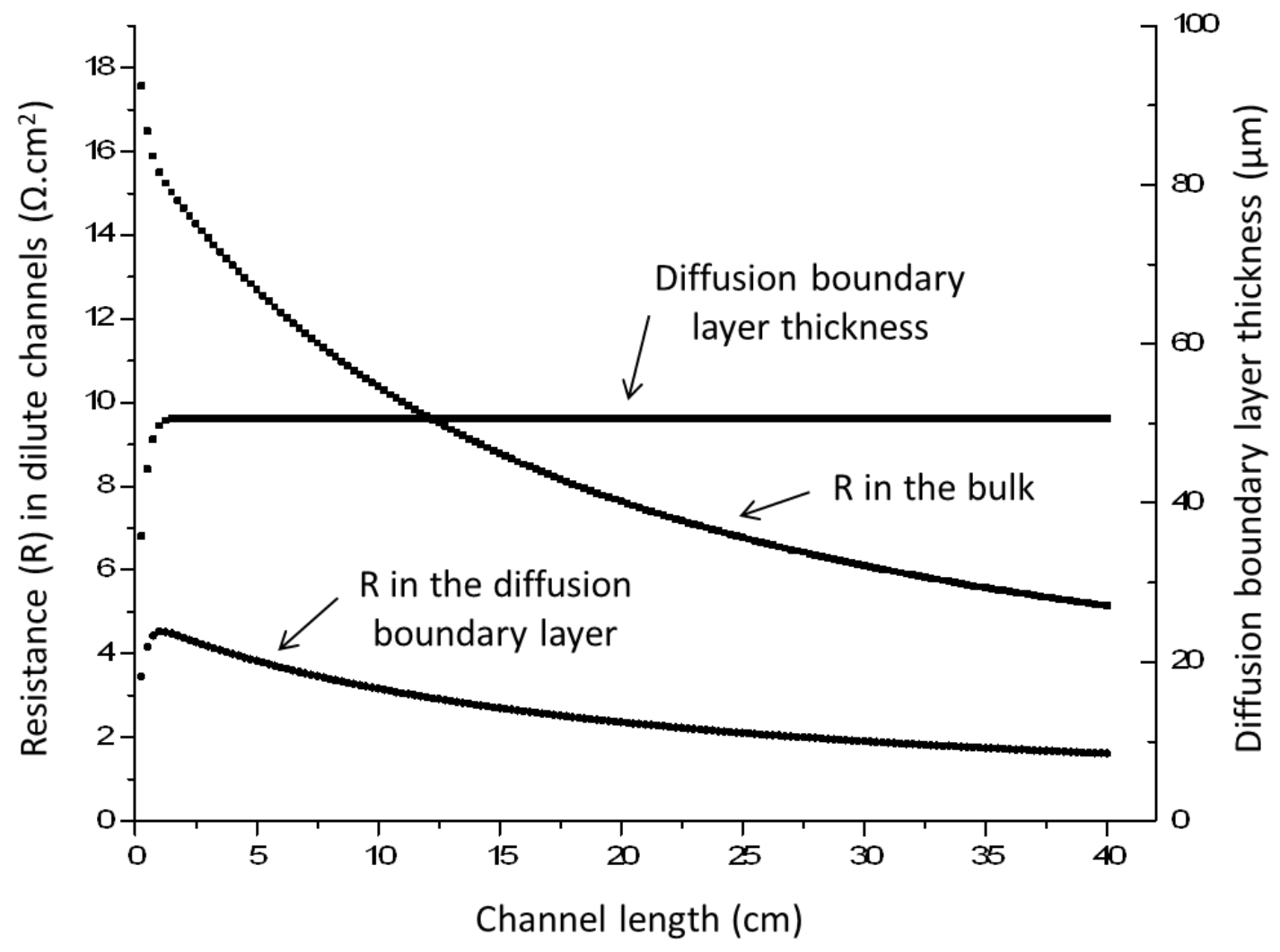

Figure A.2. Simulated local electric resistance values and diffusion boundary layer thickness in RED stack channels for a dilute saline stream solution.

The resistance of the dilute saline stream in the bulk decreases along the channel length as the solution becomes more concentrated. For the liquid diffusion boundary layer, there are two effects observed. The DBL thickness increases until a channel length of $2 \mathrm{~cm}$, what leads to an increase in the corresponding resistance, while after this point, since the thickness of DBL stabilizes, and the solute concentration within DBL increases, the DBL resistance starts to decreases. Just for comparison, the resistance in the concentrated compartment is never higher than $1.1 \Omega . \mathrm{cm}^{2}$ for the case shown. 


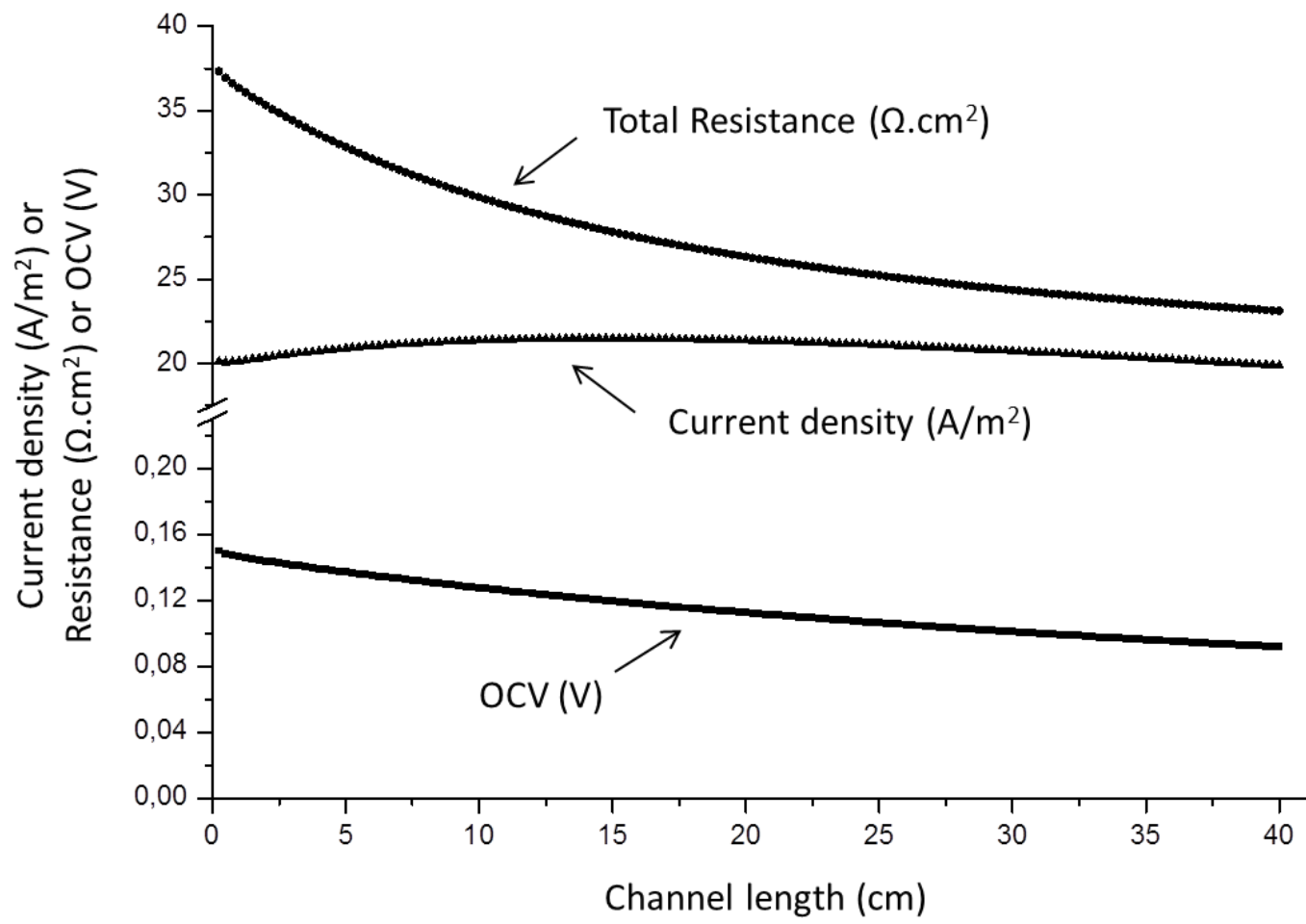

Figure A.3. Values of total electric resistance, current density and $\mathrm{OCV}$ (for $N=1$ ) along the channel length.

As expected, the OCV decreases along the channel length (Figure A.3) due to the reduction of solute concentration difference (Figure A.1). This decrease is higher close to channel entrance, when the DBL thickness is developing. The total resistance (i.e. the sum of resistances offered by the solutions, membranes and DBLs) decreases along the channel length as the dominant resistance (the dilute bulk solution resistance) has this tendency. Since the total resistance and OCV decrease along the channel length in a similar way, the current density remains almost constant at about $20 \mathrm{~A} / \mathrm{m}^{2}$.

\section{References}

[1] M. Turek, B. Bandura, Renewable energy by reverse electrodialysis, Desalination 205 (2007) 67-74.

[2] J.W. Post, H.V.M. Hamelers, C.J.N. Buisman, Energy recovery from controlled mixing salt and fresh water with a reverse electrodialysis system, Environ. Sci. Technol. 42 (2008) 57855790 .

[3] B.E. Logan and M. Elimelech, Membrane-based processes for sustainable power generation using water, Nature 488 (2012) 313-319. 
[4] G.Z. Ramon, B.J. Feinberg, E.M.V. Hoek, Membrane-based production of salinity-gradient power, Energy Environ. Sci. 4 (2011) 4423-4434.

[5] J. Veerman, M. Saakes, S.J. Metz, G.J. Harmsen, Reverse electrodialysis: Performance of a stack with 50 cells on the mixing of sea and river water, J. Membr. Sci. 327 (2009) 136-144.

[6] J. Balster, D.F. Stamatialis, M. Wessling, Membrane with integrated spacer, J. Membr. Sci. 360 (2010) 185-189.

[7] D.A. Vermaas, M. Saakes, K. Nijmeijer, Enhanced mixing in the diffusive boundary layer for energy generation in reverse electrodialysis, J. Membr. Sci. 453 (2014) 312-319.

[8] P. Dlugolecki, A. Gambier, K. Nijmeijer, M. Wessling, Practical potential of reverse electrodialysis as process for sustainable energy generation, Environ. Sci. Technol. 43 (2009) 6888-6894.

[9] P. Dlugolecki, J. Dabrowska, K. Nijmeijer, M. Wessling, lon conductive spacers for increased power generation in reverse electrodialysis, J. Membr. Sci. 347 (2010) 101-107.

[10] S. Pawlowski, P. Sistat, J.G. Crespo, S. Velizarov, Mass transfer in reverse electrodialysis: Flow entrance effects and diffusion boundary layer thickness, J. Membr. Sci. 471 (2014) 72-83.

[11] A. Daniilidis, D.A. Vermaas, R. Herber, K. Nijmeijer, Experimentally obtainable energy from mixing river water, seawater or brines with reverse electrodialysis, Renew. Energy 64 (2014) 123-131.

[12] D.A. Vermaas, M. Saakes, K. Nijmeijer, Power generation using profiled membranes in reverse electrodialysis, J. Membr. Sci. 385-386 (2011) 234-242.

[13] E. Brauns, Salinity gradient power by reverse electrodialysis: effect of model parameters on electrical power output, Desalination 237 (2009) 378-391.

[14] H. Strathmann, Electrodialysis, a mature technology with a multitude of new applications, Desalination 264 (2010) 268-288.

[15] I.G. Racz, J. Groot Wassink, R. Klaassen, Mass Transfer, Fluid flow and membrane properties in flat and corrugated plate hyperfiltration modules, Desalination 60 (1986) 213-222.

[16] L. Broussous, P. Schmitz, H. Boisson, E. Prouzet, A. Larbot, Hydrodynamic aspects of filtration antifouling by helically corrugated membranes, Chem. Eng. Sci. 55 (2000) 5049-5057. 
[17] K. Scott, A.J. Mahmood, R.J. Jachuck, B. Hu, Intensified membrane filtration with corrugated membranes, J. Membr. Sci. 173 (2000) 1-16.

[18] K. Scott, R.J. Jachuck, D. Hall, Crossflow microfiltration of water-in-oil emulsions using corrugated membranes, Sep. Purif. Technol. 22-23 (2001) 431-441.

[19] P.Z. Culfaza, M. Wessling, R.G.H. Lammertink, Hollow fiber ultrafiltration membranes with microstructured inner skin, J. Membr. Sci. 369 (2011) 221-227.

[20] A.M. Peters, R.G.H. Lammertink, M. Wessling, Comparing flat and micro-patterned surfaces: Gas permeation and tensile stress measurements, J. Membr. Sci. 320 (2008) 173178.

[21] A.M. Gronda, S. Buechel, E.L. Cussler, Mass transfer in corrugated membranes, J. Membr. Sci. 165 (2000) 177-187.

[22] C. Larchet, V.I. Zabolotsky, N. Pismenskaya, V.V. Nikonenko, A. Tskhay, K. Tastanov, G. Pourcelly, Comparison of different ED stack conceptions when applied for drinking water production from brackish waters, Desalination 222 (2008) 489-496.

[23] N. Tzanetakis, W.M. Taama, K. Scott, R.J.J. Jachuck, The effect of corrugated membranes on salt splitting, J. Appl. Electrochem. 33 (2003) 411-417.

[24] V.I. Vasileva, E.A. Goleva, Selective separation of sodium ions from a mixture with phenylalanine by Donnan dialysis with a profiled sulfogroup cation exchange membrane, Russ. J. Phys. Chem. A 87 (11) (2013) 1895-1901.

[25] E. Guler, R. Elizen, M. Saakes, K. Nijmeijer, Micro-structured membranes for electricity generation by reverse electrodialysis, J. Membr. Sci. 458 (2014)136-148.

[26] D.A. Vermaas, D. Kunteng, M. Saakes, K. Nijmeijer, Fouling in reverse electrodialysis under natural conditions, Water Res. 47 (2013) 1289-1298.

[27] D.A. Vermaas, M. Saakes, K. Nijmeijer, Early detection of preferential channeling in reverse electrodialysis, Electrochim. Acta 117 (2014) 9- 17.

[28] L. Gurreri, M. Ciofalo, A. Cipollina, A. Tamburini, W. Baak, G. Micale, CFD modelling of profiled-membrane channels for reverse electrodialysis, Desalination Water Treat., DOI: 10.1080/19443994.2014.940651. 
[29] J. Balster, M.H. Yildirim, D.F. Stamatialis, R. Ibanez, R.G.H. Lammertink, V. Jordan, M. Wessling, Morphology and microtopology of cation-exchange polymers and the origin of the overlimiting current, J. Phys. Chem. B 111 (2007) 2152-2165.

[30] M.S. Isaacson, A.A. Sonin, Sherwood number and friction factor correlations for clectrodialysis systems, with application to process optimization, Ind. Eng. Chem. Process Des. Dev. 15 (1976) 313-321.

[31] H.J. Lee, H. Strathmann, S.H. Moon, Determination of the limiting current density in electrodialysis desalination as an empirical function of linear velocity, Desalination 190 (2006) 43-50.

[32] V. Geraldes, M.D. Afonso, Limiting current density in the electrodialysis of multi-ionic solutions, J. Membr. Sci. 360 (2010) 499-508.

[33] J.G.D. Tadimeti, A. Chandra, S. Chattopadhyay S, Optimum concentrate stream concentration in $\mathrm{CaCl}_{2}$ removal from sugar solution using electrodialysis, J.Chem. Eng. Process Technol. 6 (2015) 1-13.

[34] V.V. Nikonenko, N.D. Pismenskaya, A.G. Istoshin, V.I. Zabolotsky, A.A. Shudrenko, Description of mass transfer characteristics of ED and EDI apparatuses by using the similarity theory and compartmentation method, Chem. Eng. Process. 47 (2008) 1118-1127.

[35] J.L.C. Santos, V. Geraldes, S. Velizarov, J.G. Crespo, Investigation of flow patterns and mass transfer in membrane module channels filled with flow-aligned spacers using computational fluid dynamics (CFD), J. Membr. Sci. 305 (2007) 103-117.

[36] F. Li, W. Meindersma, A.B. de Haan, T. Reith, Optimization of commercial net spacers in spiral wound membrane modules, J. Membr. Sci. 208 (2002) 289-302.

[37] R. Kodym, F. Vlasak, D. Snita, A. Cernin, K. Bouzek, Spatially two-dimensional mathematical model of the flow hydrodynamics in a channel filled with a net-like spacer, J. Membr. Sci. 368 (2011) 171-183.

[38] L. Gurreri, A. Tamburini, A. Cipollina, G. Micale, CFD analysis of the fluid flow behavior in a reverse electrodialysis stack, Desalination Water Treat. 48 (2012) 390-403.

[39] A. Tamburini, G. Barbera, A. Cipollina, M. Ciofalo, G. Micale, CFD simulation of channels for direct and reverse electrodialysis, Desalination Water Treat. 48 (2012) 370-389. 
[40] S.B. Beale, Use of streamwise periodic boundary conditions for problems in heat and mass transfer, J. Heat Transfer 129(4) (2006) 601-605.

[41] J. Welty, C. Wicks, R. Wilson, G. Rorrer, Fundamentals of momentum, heat, and mass transfer, 5th Edition, Wiley, Danvers - USA (2008), (pp. 305-307, 524-533, 542-545).

[42] L. Gurreri, A. Tamburini, A. Cipollina, G. Micale, M. Ciofalo, CFD prediction of concentration polarization phenomena in spacer-filled channels for Reverse Electrodialysis, J. Membr. Sci. 468 (2014) 133-148.

[43] D.A. Vermaas, M. Saakes, K. Nijmeijer, Doubled power density from salinity gradients at reduced intermembrane distance, Environ. Sci. Technol. 45 (2011) 7089-7095.

[44] J. Veerman, M. Saakes, S.J. Metz, G.J. Harmsen, Electrical power from sea and river water by reverse electrodialysis: A first step from the laboratory to a real power plant, Environ. Sci. Technol. 44 (2010) 9207-9212.

[45] P. Dlugolecki, P. Ogonowski, S.J. Metz, M. Saakes, K. Nijmeijer, M. Wessling, On the resistances of membrane, diffusion boundary layer and double layer in ion exchange membrane transport, J. Membr. Sci. 349 (2010) 369-379.

[46] R.W. Baker, Membrane technology and applications, Second edition, Wiley, Chichester, (2004) 411-415.

[47] D.A. Vermaas, E. Guler, M. Saakes, K. Nijmeijer, Theoretical power density from salinity gradients using reverse electrodialysis, Energy Proc. 20 (2012) 170 - 184.

[48] M. Tedesco , A. Cipollina , A Tamburini , W. van Baak, G. Micale, Modelling the reverse electrodialysis process with seawater and concentrated brines, Desalination Water Treat. 49 (2012) 404-424.

[49] A. Kozmai, V. Nikonenko, N. Pismenskaya, O. Pryakhina, P. Sistat, G. Pourcelly, Diffusion layer thickness in a membrane system as determined from voltammetric and chronopotentiometric data, Russ. J. Electrochem. 46 (2010) 1383-1389.

[50] J. Veerman, M. Saakes, S.J. Metz, G.J. Harmsen, Reverse electrodialysis: A validated process model for design and optimization, Chem. Eng. J. 166 (2011) 256-268. 
[51] M. Tedesco, A. Cipollina, A. Tamburini, I.D.L. Bogle, G. Micale, A simulation tool for analysis and design of reverse electrodialysis using concentrated brines, Chem. Eng. Res. Des. 93 (2015) 441-456.

[52] D.A. Vermaas, J. Veerman, N. Yip, M. Elimelech, M. Saakes, K. Nijmeijer, High efficiency in energy generation from salinity gradients with reverse electrodialysis, Sustain. Chem.Eng. 1(10) (2013) 1295-1302.

[53] N. Pismenskaya, V. Nikonenko, E. Belova, G. Lopatkova, P. Sistat, G. Pourcelly, K. Larshe, Coupled convection of solution near the surface of ion exchange membranes in intensive current regimes, Russ. J. Electrochem. 43 (2007) 307-327.

[54] E. Belova, G. Lopatkova, N. Pismenskaya, V. Nikonenko, C. Larchet, G. Pourcelly, Effect of anion-exchange membrane surface properties on mechanisms of overlimiting mass transfer, J. Phys. Chem. B 2006, 110, 13458-13469.

[55] R. Valerdi-Perez, J. Mengual, Current-voltage curves for an electrodialysis reversal pilot plant: determination of limiting currents, Desalination 141 (2001) 23-37.

[56] H. Jeong, H. Kim, D. Kim, Numerical analysis of transport phenomena in reverse electrodialysis for system design and optimization, Energy 68 (2014) 229-237.

[57] J. Kim, S.J. Kim, D. Kim, Energy harvesting from salinity gradient by reverse electrodialysis with anodic alumina nanopores, Energy 51 (2013) 413-421.

[58] P. Dlugolecki, K. Nymeijer, S. Metz, M. Wessling, Current status of ion exchange membranes for power generation from salinity gradients, J. Membr. Sci. 319 (2008) 214-222.

[59] J. Veerman, J.W. Post, M. Saakes, S.J. Metz, G.J. Harmsen, Reducing power losses caused by ionic shortcut currents in reverse electrodialysis stacks by a validated model, J. Membr. Sci. 310 (2008) 418-430.

[60] J. Veerman, R.M. de Jong, M. Saakes, S.J. Metz, G.J. Harmsen, Reverse electrodialysis: Comparison of six commercial membrane pairs on the thermodynamic efficiency and power density, J. Membr. Sci. 343 (2009) 7-15.

[61] S. Pawlowski, J.G. Crespo, S. Velizarov, Pressure drop in reverse electrodialysis: Experimental and modeling studies for stacks with variable number of cell pairs, J. Membr. Sci. 462 (2014) 96-111. 
[62] OpenFOAM, http://www.openfoam.org

[63] MEGA a.s., Division of electrodialysis technology, Straz pod Ralskem, Czech Republic, http://www.mega.cz

[64] K. Scott, J. Lobato, Mass transfer characteristics of cross-corrugated membranes, Desalination 146 (2002) 255-258.

[65] M. Ansari, K. Kim, Shape optimization of a micromixer with staggered herringbone groove, Chem. Eng. Sci. 62 (2007) 6687 - 6695.

[66] A.D. Stroock, S.K. Dertinger, A. Ajdari, I. Mezic, H.A. Stone, G.M. Whitesides, Chaotic mixer for microchannels. Science 295 (2002) 647-651.

[67] C. Rodrigues, V. Geraldes, M. Pinho, V. Semiao, Mass-transfer entrance effects in narrow rectangular channels with ribbed walls or mesh-type spacers, Chem. Eng. Sci. 78 (2012) 38-45.

[68] I. S. Ngene, R.G.H. Lammertink, M. Wessling, W.G.J. Van der Meer, Particle deposition and biofilm formation on microstructured membranes, J. Membr. Sci. 364 (2010) 43-51.

[69] D. Lin, F. He, Y. Liao, J. Lin, C. Liu, J. Song, Y. Cheng, Three-dimensional staggered herringbone mixer fabricated by femtosecond laser direct writing, J. Opt. 15 (2013) 1-5.

[70] D.R. Mott, P.B. Howell, J.P. Golden, C.R. Kaplan, F.S. Ligler, E.S. Oran, Toolbox for the design of optimized microfluidic components, Lab Chip 6 (2006) 540-549.

[71] J. Kuleszo, C. Kroeze, J.W. Post, B.M. Fekete, The potential of blue energy for reducing emissions of CO2 and non-CO2 greenhouse gases, J. Integr. Environ. Sci. 7 (S1) (2010) 89-96.

[72] S. Pawlowski, C.F. Galinha, J.G. Crespo, S. Velizarov, 2D fluorescence spectroscopy for monitoring ion-exchange membrane based technologies - Reverse electrodialysis (RED), Water Res. 88 (2016) 184-198.

[73] S. Pawlowski, C.F. Galinha, J.G. Crespo, S. Velizarov, Prediction of reverse electrodialysis performance by inclusion of 2D fluorescence spectroscopy data into multivariate statistical models, Sep. Purif. Technol. 150 (2015) 159-169. 
[74] A. Daniilidis, R. Herber, D.A. Vermaas, Upscale potential and financial feasibility of a reverse electrodialysis power plant, Appl. Energy 119 (2014) 257-265.

[75] D.A. Vermaas, $\mathrm{PhD}$ thesis, Energy generation from mixing salt water and fresh water, University of Twente, The Netherlands, 2013, pp. 239-241. 